\title{
TERRITÓRIOS DA MIGRAÇÃO NA CIDADE DE SÃo PAUlo: ENTRE A AFIRMAÇÃo E NEGAÇÃO DA CONDIÇÃO MIGRANTE
}

Odair da Cruz Paiva*

\section{Introdução}

A alteração de espaços urbanos por grupos de migrantes é uma das características mais comuns da dinâmica dos deslocamentos populacionais. A análise das transformações no espaço promovidas pelos processos migratórios coloca em discussão as implicações econômicas, culturais, históricas as contradições da presença dos territórios da migração, especialmente em cidades como São Paulo. Dentre os vários trabalhos que analisaram processos de ocupação territorial, o estudo de CYMBALISTA e XAVIER (1997) $)^{1}$ apresenta um esforço em caracterizar quatro padrões de ocupação territorial (territórios étnicos), são eles: os guetos norte-americanos, os banlieues das grandes cidades francesas, os enclaves étnicos e os loteamentos ilegais formados por comunidades perseguidas por motivações religiosas ou políticas. Estes territórios expressam a capacidade de determinadas comunidades em produzir ambientes que expressam as marcas de sua presença.

* Professor do Departamento de História da Universidade Federal de São Paulo, pesquisador do NEPO - UNICAMP e do Museu da Imigração - São Paulo.

${ }^{1}$ CYMBALISTA, Renato e XAVIER, Iara Rolnik. "A comunidade boliviana em São Paulo: definindo padrões de territorialidade." In: Cadernos Metrópole, n. 17, pp. 119-133, $1^{\circ}$. sem. 1997. 
$\mid 14$ |

Territórios da migração na cidade de São Paulo: Entre a afirmação e...

A percepção de que determinadas porções da cidade guardam características arquitetônicas, culturais, humanas e econômicas singulares é abertura para um olhar mais atento a seus elementos históricos estruturantes e sua transformação no tempo. O bairro da Liberdade em São Paulo é um bom exemplo. No contexto paulistano, ele é rememorado como um bairro japonês muito embora atualmente, a presença de chineses e coreanos seja cada vez mais intensa. Este adensamento de fluxos migratórios altera a dinâmica do vivido naquele espaço e torna mais complexa sua dinâmica social, econômica e cultural.

Bairros como o Bom Retiro, Brás, Mooca ou Pari, são também exemplos de territórios migrantes que sofreram transformações significativas na sua paisagem no transcurso do século XX. A sobreposição de correntes migratórias num mesmo espaço transformou o Bom Retiro; de bairro judeu a partir da primeira metade do século $\mathrm{XX}$, a presença de coreanos e bolivianos é predominante nos dias de hoje. Processo semelhante ocorreu com o Brás e a Mooca; redutos de italianos, espanhóis e portugueses estes foram paulatinamente transformados pela presença de migrantes nordestinos.

As metamorfoses de muitos bairros de São Paulo durante o século XX e início deste é um tema importante nos estudos sobre a urbanização e migração. ${ }^{2}$ A proposição deste artigo é discutir alguns elementos da relação entre os processos migratórios e a constituição de territórios da migração decodificando suas aproximações e diferenças. A análise dessa relação abre caminho para inserir na pauta dos estudos de

\footnotetext{
${ }^{2}$ Dentre muitos trabalhos, ver: MAGNANI, José Guilherme Cantor. Festa no Pedaço: cultura popular e lazer na cidade de São Paulo. São Paulo: Hucitec, 1998; SANTOS, Milton. O Espaço do Cidadão. São Paulo: Nobel, 1998; SINGER, Paul. Economia Política da urbanização. São Paulo: Contexto, 1998 e VERAS, Maura. "Territorialidade e Cidadania em Tempos Globais: imigrantes em São Paulo". In: Cadernos Metrópole (PUC-SP), v. 2 (1999): 73-119; da mesma autora: Diver(cidade): territórios estrangeiros como topografia da alteridade em São Paulo. São Paulo: Educ, 2003.
}

Migrações 
migração o fato da constituição destes territórios enquanto uma expressão ambígua da afirmação e da negação da condição migrante. Este artigo está estruturado em três momentos. No primeiro, uma apreensão mais geral sobre a constituição dos territórios da migração sua variedade e complexidade; no segundo, alguns exemplos desses territórios na cidade de São Paulo e a decodificação de suas singularidades e semelhanças; no terceiro momento, os territórios enquanto expressão ambígua da afirmação e negação da condição migrante.

\section{Territórios da migração: apontamentos}

A relação entre os deslocamentos populacionais e a constituição de territórios, nos leva a uma breve digressão sobre dois elementos. Trata o primeiro, da noção de território que embasa essa reflexão; este representa um complexo de relações econômicas, sociais, históricas, culturais, ambientais e políticas erigidas num dado espaço (geográfico) e cuja constituição guarda conexões amplas e variadas com outros territórios. Ele adensa camadas de tempo; supõe características que lhe são singulares ao passo em que se constitui enquanto totalidade aberta a transformações no transcurso da história. Resulta de necessidades e motivações múltiplas de seus sujeitos; estas podem ser de ordem material e concreta (relações econômicas) ou de natureza por vezes intangível como as necessidades da cultura, das sociabilidades, elos de pertencimento, etc.

$$
\text { Segundo SAYAD (1998): }
$$

(...) o espaço dos deslocamentos não é apenas um espaço físico, ele é também um espaço qualificado em muitos sentidos, socialmente, economicamente, politicamente, culturalmente (sobretudo através das duas realizações culturais que são a língua e a religião), etc. (1990, p. 15)

${ }^{3}$ SAYAD, Abdelmalek. A Imigração ou os Paradoxos da Alteridade. São Paulo: Editora da USP, 1998. 
| 16 |

Territórios da migração na cidade de São Paulo: Entre a afirmação e...

Trata o segundo elemento do fato das migrações serem, de um lado, um fenômeno social complexo e, de outro, constituíremse enquanto um processo sempre coletivo, eivado por redes sociais que lhe dão suporte. Nesta perspectiva, as migrações são portadoras de uma multiplicidade de sentidos que transcendem as expectativas da sociedade receptora. Em outros termos, ao passo em que há uma tendência da sociedade de destino em aceitar os migrantes apenas enquanto força-trabalho, as migrações subvertem esse sentido redutor de suas potencialidades imposto pela sociedade de recepção. As migrações criam um descompasso de expectativas que se explicitam cada vez que os migrantes demonstram sua capacidade de modificar - por vezes em grande magnitude - a sociedade de acolhida. Dessa forma, a produção dos territórios pelas migrações guarda múltiplos sentidos e contradições.

Nos núcleos coloniais, pequenas vilas e cidades como Holambra (SP), Blumenau (SC) ou São Leopoldo (RS), a arquitetura das edificações explicita de maneira contundente a presença dos migrantes. Por outro lado, os territórios também se constituem de cultura imaterial - festas, culinária ou religiosidade - que se hibrida e funde-se com as manifestações materiais. Ambos os sentidos (materiais e imateriais), constituem uma paisagem cultural que se distingue de outras, ao passo que dão singularidade ao território.

No contexto urbano, o bairro como São Miguel Paulista território nordestino na cidade de São Paulo - possui uma fixidez maior se comparado a territórios que se constituem de maneira mais efêmera e podem ser erigidos em diferentes lugares na cidade. Exemplos destas manifestações mais fluídas ou móveis são as festas que se realizam em determinadas épocas do ano ou mesmo em certos dias da semana como a feira organizada por migrantes bolivianos na Praça Kantuta no bairro do Pari. Fixidez e fluidez são termos pouco apropriados para a qualificação destes territórios mas respondem aos sentidos materiais e intangíveis que permeiam os territórios migrantes.

Construídos paulatinamente, os territórios materializam necessidades múltiplas que vão deste a tentativa de recriação de 
paisagens assemelhadas às das sociedades de origem até a manutenção de vínculos e elos de pertencimento entre os migrantes - elementos de suporte fundamental para sobreviver enquanto se considera estar no território de outrem. Dessas necessidades (materiais e afetivas, concretas e identitárias) a produção do espaço-território obedece às singularidades e tempos de inserção dos migrantes.

Os territórios da migração não são espaços idílicos ou folclóricos - embora também possam assim parecer. Eles se constituem enquanto ação-reação na constante disputa por inserção, pertencimento e visibilidade nos contextos urbanos ou rurais. São totalidades complexas que se constroem sobrepondose e ocultando outros sujeitos, outras sociabilidades, outros territórios. Como teremos oportunidade de observar adiante, transformam-se; alguns a ponto de negar parte de suas origens. Por vezes são compreendidos como intrusos pela sociedade de recepção dado que adensam e materializam a presença do outro, do estrangeiro, do invasor, daqueles que portam costumes, hábitos e culturas singulares, incômodas ou perigosas ${ }^{4}$.

Não há que se buscar uma homogeneidade nos territórios da migração. O território tipicamente ou exclusivamente nordestino, coreano, italiano, chinês ou árabe a rigor não existe. Os territórios da migração são híbridos, apesar de singularidades que lhes conferem certa identidade. Por este caminho, não ouso propor uma tipologia de territórios da migração, mas sim uma descrição preliminar de suas composições. São Miguel Paulista: o território cuja paisagem é marcada por elementos materiais e

\footnotetext{
${ }^{4}$ Este tema é recorrente e importante nos estudos de migração no Brasil e está presente em vários trabalhos; dentre eles, destaco apenas dois. O trabalho de Lesser, sobre a imigração de japoneses e chineses e o estudo de Naxara sobre a inserção de migrantes brasileiros em São Paulo. Ver: LESSER, Jeffrey. A Negociação da Identidade Nacional. Imigrantes, minorias e a luta pela etnicidade no Brasil. São Paulo: Editora UNESP, 2001. NAXARA, Márcia Regina Capelari. Estrangeiro em sua Própria Terra. Representações do Brasileiro. 1870/1920. São Paulo: Annablume/FAPESP, 1998.
} 
$|18|$

Territórios da migração na cidade de São Paulo: Entre a afirmação e...

imateriais que denotam a presença e persistência de uma identidade migrante singular; Liberdade: o território no qual, apesar de uma singularidade aparente, há um vivido híbrido que convive com diferentes tempos históricos e a feira da Praça Kantuta, território móvel, visível e invisível.

\section{Territórios da migração}

\section{São Miguel Paulista}

A transformação do bairro de São Miguel Paulista (localizado na zona leste da cidade) em território nordestino remonta aos anos 1930. Até as primeiras décadas do século XX, o bairro abastecia a região central da Capital com hortaliças, legumes e frutas. Sua população constituía-se de pequenos produtores rurais, notadamente imigrantes portugueses e posteriormente japoneses; as plantações naquela área, como em muitas outras da cidade, formavam uma espécie de cinturão-verde. São Miguel também concentrava algumas olarias que produziam para a construção civil na cidade.

Segundo BOMTEMPI (1970)

Após 1935 o padrão de ocupação do bairro se altera. As chácaras paulatinamente dão lugar aos arruamentos e loteamentos, dando lugar aos trabalhadores da indústria (Nitro-Química) ou de trabalhadores dos estabelecimentos de outras partes da cidade. Estes loteamentos têm sua fase áurea no período da II Guerra Mundial quando chegam ao bairro levas de trabalhadores rurais e de outras partes do Brasil. (1970, p. 159-160).

\footnotetext{
${ }^{5}$ BOMTEMPI, Sylvio. O bairro de São Miguel Paulista: A Aldeia de São Miguel de Ururaí na História de São Paulo. São Paulo: Divisão do Arquivo Histórico. Departamento de Cultura/Secretaria de Educação e Cultura, 1970.
} 
A instalação da Companhia Nitro-Química Brasileira ${ }^{6}$ no bairro em 1935 foi fator decisivo para o afluxo e fixação de migrantes nordestinos. A inserção destes novos sujeitos transformou antigos territórios e sociabilidades, ao passo que implantou novos elementos na paisagem. Como toda migração, a chegada de nordestinos em São Paulo constituiu-se por redes sociais que a retroalimentaram.

Em várias entrevistas com migrantes que se fixaram no bairro durante os anos 1930 e 1940 encontram-se elementos como os expressos abaixo.

Eu vim de Senhor do Bonfim, Estado da Bahia. Ali em 1938, 1940 ia algumas pessoa daqui prá lá e chegava lá e dizia que aqui era uma beleza (...) que aqui era bonito, tinha muito dinheiro (...) e aquilo acabou me atraindo. (...) São Paulo a gente chegava aqui, todo mundo conhecia a estação Roosevelt, naquela época era a estação do Norte, que todo mundo que era do Norte vinha ali (...) e dalí para a estação de São Miguel. Quem tinha familiares aqui, procurava a Nitroquímica. Às vezes (...) ela chegava na portaria e dizia para o chefe da guarda. "eu sou parente de fulano de tal" (...) se ele tava trabalhando quando ele saía, ele pegava a pessoa, se não quando saísse um conhecido daquela pessoa a gente pegava e levava até a cada dele (...) Cheguei numa quinta-feira, (...) na segunda-feira já comecei a trabalhar (...) $)^{7}$

${ }^{6}$ Sobre a constituição do Bairro de São Miguel Paulista e da Companhia Nitroquimica ver: PAIVA, Odair da Cruz. Caminhos Cruzados. Bauru: Edusc, 2004; ROCHA, Antonia Sarah Aziz. O bairro à sombra da chaminé: um estudo sobre a formação da classe trabalhadora da Companhia Nitro Química de São Miguel Paulista (1935-1960. Dissertação (Mestrado em educação). Pontifícia Universidade Católica de São Paulo, 1992; FONTES, Paulo. Trabalhadores e cidadãos: Nitro-Química: a fábrica e as lutas operárias nos anos 50. São Paulo: Annablume, 1997.

${ }^{7}$ Excerto de entrevista realizada pelo autor com o Sr.Carlos (nome fictício) em 30/4/1999 na sub-sede do Sindicato dos Químicos em São Miguel Paulista. 
$|20|$

Territórios da migração na cidade de São Paulo: Entre a afirmação e...

São Miguel Paulista foi reincorporado à cidade num processo que possuía, de um lado, os reflexos da periferização crescente da malha urbana a partir dos anos 1930 e de outro, pela inserção de atividades industriais - como foi o caso da NitroQuímica. Lugar de terrenos mais baratos, São Miguel (que incluía também Itaquera e Guaianazes) recebeu entre as décadas de 1940 a 1970 milhares de migrantes, nominados de forma redutora como baianos ${ }^{8}$.

O território com características rurais e povoado por migrantes portugueses e japoneses foi transformado em território nordestino.

Nas palavras de um migrante,

Tudo isso dava ao bairro um clima de festa (...) de retorno (...) a gente se sentia no próprio sertão9.

Tudo isso é uma referência a um conjunto de elementos concretos e simbólicos erigidos na paisagem do bairro. Das Casas do Norte e dos forrós aos encontros nas praças; das conversas sobre as viagens mais ou menos constantes nas quais se trocam informações sobre os parentes de lá aos presentes e lembranças que vão e vem; da liberdade da fala com sotaque sem temer o olhar alheio a um sentido de pertencimento a cidade. Operouse em São Miguel o adensamento de uma nova dinâmica do vivido que ocultou, desagregou e transformou sociabilidades pretéritas.

Por outro lado, São Miguel, enquanto um território da migração não é um espaço exclusivo da festa. Tensões e preconceitos também marcaram sua constituição. Talvez um dos casos mais emblemáticos tenha sido a querela que circundou

\footnotetext{
${ }^{8}$ Henri Arraes Gervaiseau dirigiu em 1994 um documentário intitulado Tem Que ser Baiano; nele temos com clareza - nos depoimentos de vários migrantes nordestinos - o sentido redutor da identidade, subjacente à aplicação do termo baiano.

${ }^{9}$ Excerto de entrevista realizada pelo autor com o Sr.Antonio (nome fictício) em 30/4/1999 na sub-sede do Sindicato dos Químicos em São Miguel Paulista.
}

Migrações 
a mudança do nome do bairro em 1944. Até então, seu nome era São Miguel de Ururaí, lembrança do antigo aldeamento de índios guaianazes organizado por padres jesuítas em $1590^{10}$. Naquele ano, por iniciativa do poder público, o bairro perdeu seu antigo nome para Baquirivú. A mudança desagradou os moradores, que organizaram um processo de coleta de assinaturas para uma nova mudança no nome do bairro.

De acordo com BOMTEMPI (1970), a escolha foi feita a partir de três opções: São Miguel Baquirivú, São Miguel Paulista e São Miguel Bahia. O maior número de assinaturas deu vitória a São Miguel Paulista. Segundo o depoimento de um antigo morador do bairro que participou da coleta de assinaturas para a mudança do nome do bairro, registrado por ROCHA $(1992)^{11}$ :

Naquela época havia grande rejeição em relação aos
primeiros moradores do bairro, ou seja, os índios.
Os índios (...) eram vistos como povo bem atrasado,
pobre e sem tradição. Muitos moradores que para
cá vieram tinham vergonha de mencionar que São
Miguel tinha sido aldeia indígena. Quanto ao nome
São Miguel Bahia nem gosto de falar! Na época houve
muito desprezo por este nome. Era um certo
preconceito, uma rejeição... sei lá! O preconceito
sempre existiu aqui. Os baianos eram chamados de
"cabeça chata", "pau-de-arara" e outros. Saiu muita
briga por isto e até morte. Acredito que tudo isto
ajudou para que a escolha do nome fosse São Miguel
Paulista. Nome de Santo o povo sempre aceita...
e santo paulista ... tanto melhor. (1992, p. 24)

${ }^{10}$ São Miguel de Ururaí era a junção do nome do santo padroeiro da capela construída em 1580, São Miguel Arcanjo, com o nome da aldeia indígena, Ururaí.

${ }^{11}$ ROCHA, Antonia Sarah Aziz. O bairro à sombra da chaminé: um estudo sobre a formação da classe trabalhadora da Companhia Nitro Química de São Miguel Paulista (1935-1960). Dissertação (Mestrado em educação). Pontifícia Universidade Católica de São Paulo, 1992. 
A escolha do novo nome para o bairro é emblemática. A partir do momento em que os nordestinos se fixavam na cidade, reconstruíam suas vidas e interagiam com o novo lugar, a mudança do nome do bairro mascarava transformações que estavam em curso. São Paulo silenciava sua porção nordestina; os territórios são por vezes, indesejáveis.

Os territórios da migração nordestina em São Paulo - presentes também em bairros da zona sul como Santo Amaro talvez sejam os que absorveram levas sucessivas de migrantes durante mais tempo. Ao contrário da imigração italiana, espanhola, portuguesa e japonesa, cuja intensidade se circunscreve num espaço de tempo mais restrito, a entrada de nordestinos em São Paulo foi intensa durante mais de quatro décadas. Isto conferiu a estes territórios certa perenidade no ambiente urbano dado que foram retroalimentados por sujeitos oriundos de uma mesma região. Penso que este dado é importante já que ele nos permite pensar a constituição de outro território da migração: o bairro da Liberdade.

\section{Liberdade}

O bairro da Liberdade localiza-se na área central da cidade e se estende sentido sul a partir da Sé. Seus limites estão mais ou menos definidos num semicírculo a partir do qual encontramos os bairros do Cambuci, Bela Vista (Bexiga) e partes da Consolação. Até fins do século XIX esta área não fazia parte do perímetro central da cidade, algo que ocorreu com rapidez no princípio do século XX dada a expansão da rede de bondes, esgoto, água encanada e iluminação pública. Entre as décadas finais do século XIX e inícios do século XX, a abolição da escravidão, a instauração da República e a imigração promoveram alterações significativas nesta porção da cidade. Segundo ROLNIK $(1997)^{12}$,

\footnotetext{
${ }^{12}$ ROLNIK, Raquel. A Cidade e a Lei. Legislação, política urbana e territórios na cidade de São Paulo. São Paulo: Studio Nobel: Fapesp, 1997.
} 


\begin{abstract}
Com a redefinição do espaço urbano que ocorreu com a abolição da escravidão, a imigração maciça de europeus e a dinâmica da economia do café, novos territórios negros foram estabelecidos: nos porões e nos cortiços do centro velho, sobretudo no sul da Sé, na área que não foi objeto de muitas remodelações, na região do Lavapés (contígua ao sul da Sé) e nos campos do Bexiga. (1997, p. 75)
\end{abstract}

Ocorre que a redefinição de porções daquele espaço urbano - promovida pela migração da população negra expulsa das áreas mais centrais no processo de higienização da cidade - foi seguida da sua apropriação pelos migrantes italianos e seus descendentes, além de acolher a migração japonesa. Num espaço de quatro décadas entre o final do século XIX e início do XX este adensamento de populações de origens variadas fez da Liberdade um lugar singular no contexto dos territórios da migração na cidade.

Atualmente encontramos na Liberdade uma das associações italianas mais antigas de São Paulo, a Lega Italica (1897), a Casa de Portugal e uma das mais tradicionais casas de artigos religiosos voltados para cultos africanos; esta se localiza na Praça da Liberdade, ícone e epicentro da presença japonesa na cidade. Este adensamento híbrido distingue a Liberdade de São Miguel Paulista.

A fixação de japoneses na Liberdade remonta ao início do século $X X^{13}$. Em 1912, um grupo de imigrantes fixa-se na Rua Conde de Sarzedas atraídos por aluguéis baratos e pela proximidade com o centro da cidade. Em pouco tempo, emergem na paisagem do bairro empórios, hospedaria e pequenos estabelecimentos de produção e comércio de gêneros alimentícios direcionados para os migrantes japoneses. A escola primária data de 1915 (Escola Primária Taisho); um ano antes, foi fundado o Hotel Ueji.

${ }^{13}$ Informações extraídas de: http://www.culturajaponesa.com.br/htm/ historiadaliberdade.html, acessado em 10/08/2010. 
| 24 |

Territórios da migração na cidade de São Paulo: Entre a afirmação e...

Para além da Rua Conde de Sarzedas, a comunidade passa a ocupar ruas próximas: Conde do Pinhal, Conselheiro Furtado, Irmã Simpliciana e Tomás de Lima. Nos anos 1960 a Liberdade já contava com quatro cinemas (Cine Niterói, Nippon, Jóia e Tóquio) freqüentados pela comunidade ávida pelos filmes produzidos no Japão. Uma associação cultural (o Bunkyô, que abriga hoje o Museu da Imigração Japonesa) e associações de classe compunham a paisagem desse território da migração.

Se por um lado a Liberdade tornou-se, na primeira metade do século XX um território japonês, ocultando outros sujeitos e territórios (negros e italianos), a partir dos anos 1970 o bairro recebe a migração coreana e nos anos 1980/1990 chegam os chineses. A mobilidade dos sujeitos neste território é tema importante para compreendermos a dinâmica das migrações em São Paulo; entretanto, dada a complexidade da questão e os limites deste artigo, farei apenas algumas observações.

Em primeiro lugar, os territórios da migração - como todos os outros - envelhecem. A sucessão das gerações e os processos de inserção dos descendentes de imigrantes na comunidade nacional supõem outras mobilidades. A morte dos pais, a ascensão econômica e cultural, a mudança de expectativas com relação à manutenção ou não dos negócios familiares, são fatores que fazem com que todo o conjunto de construções (materiais e simbólicas) realizado pelas primeiras gerações seja ressignificado pelas gerações seguintes.

Em segundo lugar, os territórios da migração possuem mobilidade. Entendemos isso quando percebemos que parte da comunidade judaica migra - a partir dos anos 1970/80 - do Bom Retiro para Higienópolis, abrindo espaço para que seus negócios fossem geridos pelos coreanos. Estes, a partir dos anos 1990/2000, migram para bairros como a Aclimação e abrem espaço para os migrantes bolivianos. Neste processo, o bairro paulatinamente perde sua singularidade no contexto urbano enquanto um território judeu e agrega marcas dos novos migrantes. Só com um olhar bastante atento podemos encontrar hoje as marcas 
da presença da comunidade judaica na profusão e no burburinho das ruas de comércio de confecção do Bom Retiro.

Entretanto, as transformações ocorridas no Bom Retiro ao menos no âmbito de sua paisagem concreta - não foram reeditadas na Liberdade. Em que pese o fato de parte significativa das suas lojas serem geridas por imigrantes chineses e coreanos, estes continuam se dedicando também ao comércio de produtos japoneses. Caminhando por suas ruas, encontramos na iluminação pública, na profusão de restaurantes de comida japonesa ou na publicidade com ideogramas japoneses, uma paisagem japonesa, embora seu vivido e conteúdo estejam já algo longe das suas origens.

\section{A Praça Kantuta}

A Praça Kantuta no bairro do Pari (zona norte da cidade) entra no rol de territórios da migração por suas singularidades se comparado com São Miguel Paulista e Liberdade - e por ser expressão da continuidade das migrações que, década após década, continuam moldando o espaço da cidade. A presença boliviana na cidade remonta aos anos 1950, entretanto, foi nas décadas de 1980/1990 - com a inserção destes como trabalhadores nas oficinas de costura do Bom Retiro - que a migração boliviana ganha visibilidade no espaço da cidade.

A visibilidade, aliás, foi um dos temas que circundaram os estudos produzidos sobre essa migração ainda nos anos $1980 .{ }^{14}$

A partir do final dos anos 1970 a ausência de uma política imigratória no país - cuja expressão mais emblemática foi o

\footnotetext{
${ }^{14}$ Um dos estudos pioneiros sobre a imigração boliviana, sua inserção no mundo do trabalho e a problemática da invisibilidade foi realizado por Sidney Silva. Ver: SILVA, Sidney A. Costurando Sonhos.Trajetória de um grupo de imigrantes bolivianos em São Paulo. São Paulo: Paulinas Editora, 1997. v. 01.292 p.
} 
fechamento da Hospedaria de Imigrantes no Bairro do Brás ${ }^{15}$ criou um ambiente no qual as novas levas de migrantes chegados ao país (coreanos, chineses, latino-americanos e africanos) foram permeadas por um misto de ilegalidade e invisibilidade. Indocumentados em sua maioria, os bolivianos inseriram-se num circuito da produção que se beneficiou da fragilidade de seu status ilegal.

Durante os anos 1980/90, a mão-de-obra (barata e cativa) boliviana foi fundamental para a expansão de determinados ramos da produção têxtil que abasteciam e ainda abastecem o comércio popular das ruas do Bom Retiro e as grandes redes de lojas de vestuário. $\mathrm{Na}$ época, pesquisadores procuravam mapear as condições de vida e trabalho dessa população como forma de compreender a sua invisibilidade no contexto urbano. Grande parte destes migrantes residia no local de trabalho, tinham mobilidade limitada e eram assolados pelo medo (muitas vezes imposto pelos próprios donos das oficinas) da polícia, da prisão e da deportação ${ }^{16}$. A migração boliviana em São Paulo em seus primeiros tempos foi exemplo da impossibilidade de constituição de um território migrante. Sua característica foi a de não deixar marcas na paisagem, daí sua invisibilidade.

Entretanto, este quadro foi alterado a partir do final da década de 1990 quando esses migrantes superam sua mera condição de força-trabalho e emergem como sujeitos de direitos. Atualmente, matriculam seus filhos nas escolas públicas, demandam sua inserção nos serviços públicos de saúde, organizam

\footnotetext{
${ }^{15}$ Sobre a história da Hospedaria de Imigrantes e alguns dos desdobramentos de seu fechamento para a dinâmica das migrações em São Paulo, ver: PAIVA, Odair da Cruz e MOURA, Soraya. Hospedaria de Imigrantes de São Paulo. São Paulo: Paz e Terra, 2008.

${ }^{16}$ Um excelente levantamento sobre a produção bibliográfica sobre as migrações para o país e também sobre a migração de brasileira está em: ASSIS, Glaucia de Oliveira. SASAKI, Elisa Massae. Novos Migrantes do e para o Brasil: Um Balanço da Produção Bibliográfica. In: Seminário Internacional Migrações Internacionais. Brasília: CNPD, 2000.
} 
seus times de futebol e usufruem dos espaços de lazer. É neste novo contexto de visibilidade que temos a produção de um território migrante boliviano na cidade: a Praça Kantuta no bairro do Pari.

Por volta do ano 2000, era possível observar uma concentração de imigrantes bolivianos na Praça Padre Bento (também no Pari) aos finais de semana, particularmente aos domingos. $\mathrm{Na}$ época a comunidade do em torno reagiu ao que chamaram de feira clandestina e aos transtornos causados pelo mau comportamento (alcoolismo, produção de lixo, etc.) de seus freqüentadores. Em certa medida, esse incipiente ambiente de visibilidade dos bolivianos na cidade expressava o panorama de ilegalidade da comunidade no contexto urbano. A transferência da feira para um espaço próximo ocorre entre 2001 e 2002 e em 2004 se dá a oficialização da praça com o nome Kantuta ${ }^{17}$.

A feira da Praça Kantuta representa um novo momento da relação da comunidade boliviana com a cidade; da ilegalidade à legalidade; da invisibilidade à visibilidade; do ocultamento à transparência. Este território migrante possui identidades e singularidades importantes com seus congêneres que resumirei em três breves notas. A primeira tem relação com o evento, a feira e suas características básicas de ocupação do espaço público, de lugar de trocas e sociabilidades diversas, de afirmação de identidades e integração. Nesta perspectiva, a feira da Praça Kantuta evoluiu enquanto um ícone da presença boliviana em São Paulo, enquanto um território em seu sentido mais amplo e comparável a outras feiras congêneres como a da Praça da Liberdade.

\footnotetext{
17 Kantuta designa uma flor do altiplano andino. Com cores verde, amarela e vermelha (as mesmas da bandeira da Bolívia) esta flor - segundo os próprios bolivianos - representa a união de povos e culturas e simboliza sua conexão com o país. Em 2008 com direção de Rodrigo Leite, a CTR-ECA-USP produziu o documentário Kantuta. Trata-se de um excelente registro das várias perspectivas sobre aquele território.
} 
A segunda nota é a dissociação permanente entre a feira e a praça, entre a densidade das atividades humanas e o espaço físico. A Praça Kantuta não é um território boliviano durante todo o tempo, ao contrário da Praça da Liberdade. A feira ocorre apenas aos domingos o que implica numa sazonalidade constante do território ou se preferirmos, na permanência, em certa medida, da dualidade visibilidade e invisibilidade.

Esta nota nos remete à terceira. Aos migrantes contemporâneos está dificultada a possibilidade em (re)produzir no espaço da cidade, territórios como aqueles criados por migrações mais pretéritas. Evidentemente há uma escassez de espaços que faz com que a cidade atinja um grau de adensamento físico que beira a saturação. Mas também há que se considerar uma nova dinâmica para os deslocamentos populacionais no plano mundial marcado pela pluridirecionalidade dos fluxos e pelas possibilidades intensas de conexão e trocas (via internet, telefone, televisão) entre os que migram e os que permanecem nas regiões de origem.

Quero salientar com isso que estamos num momento de revisão da compreensão que temos dos territórios da migração. O caso da migração de bolivianos - mas também da migração chinesa ou africana - apresenta novos desafios para compreendermos suas relações com a cidade e também suas estratégias de sociabilidade. Em outros termos, os territórios da migração podem estar ganhando contornos mais virtuais ao passo que a sociabilidade destes sujeitos adentra há um tempo onde as singularidades (culturais), onde as expectativas de integração (econômicas e políticas), onde os sonhos (e as utopias) sofrem interferências da homogeneização das formas do vivido na sociedade de consumo ${ }^{18}$.

Neste terreno, as singularidades são folclorizadas, as possibilidades de integração são formalizadas pelas regras já

\footnotetext{
${ }^{18}$ Sobre esta questão ver: BAUMAN, Zygmunt. Vida para Consumo. A transformação das pessoas em mercadoria. Rio de Janeiro: Zahar, 2008.
} 
estabelecidas pela economia e política, os sonhos e utopias são comprados nos shoppings centers. Estas determinações do tempo presente não são perceptíveis apenas a partir do território Kantuta. Ocorre nos territórios migrantes o mesmo fenômeno que tende no plano mundial - produzir ícones comuns a todos os povos e suprimir a importância do lugar na constituição das identidades.

\section{Considerações Finais. Territórios da Migração na Cidade de São Paulo: entre a afirmação e negação da condição migrante}

Sayad (1998) quando de sua análise sobre a imigração de argelinos na França, apontou, entre outras questões, as várias ambigüidades que cercam a condição do migrante. Uma delas tem interesse particular na reflexão sobre os territórios migrantes. Os migrantes são desejados e aceitos pela sociedade de destino apenas como força trabalho despossuída de outros interesses e expectativas. É nesta condição que a migração faz sentido, inclusive para os próprios migrantes no momento de sua decisão por trocar sua identidade de nacional para estrangeiro. Ocorre que, realizada a migração, opera-se uma transformação - ou superação - dessa condição; o migrante passa a perceber-se enquanto sujeito portador de direitos e luta pelo reconhecimento de suas singularidades.

Realiza-se neste momento, uma radical mudança no sentido de sua condição migrante. Como uma Caixa de Pandora aberta, eclodem outras potencialidades para o vivido migrante, inclusive o princípio de uma possível negação desta condição. Em outros termos, os territórios migrantes portam uma ambigüidade. Se por um lado eles expressam a reafirmação de necessidades e singularidades do outro, do não nacional, por outro lado, eles expressam a necessidade de enraizamento na sociedade de destino; esta ambigüidade se realiza de maneira particular, na medida em que só pode ser erigida numa materialização de referências que, ao mesmo tempo em que estão sendo recordadas, precisam ser perdidas. 
$130 \mid$

Territórios da migração na cidade de São Paulo: Entre a afirmação e...

As referências que o migrante erige em seus territórios são, em muitos casos, representações sobre a sociedade de origem que tendem, com o tempo, a entrar em descompasso e anacronismo com a dinâmica do vivido e das transformações operadas na sociedade de origem na sua ausência. Os territórios migrantes possuem uma função de manter unidos elementos de ligação do migrante com suas origens ao passo em que se distanciam e transformam-se no âmbito da sociedade de recepção.

Os territórios são a materialização de um momento seminal da transformação do migrante em sujeito portador de direitos. A ambigüidade (ou paradoxo) está em que eles exprimem um momento final da condição migrante justamente pela afirmação dessa mesma condição. Os territórios exprimem, assim, o início de um longo processo de negação da condição migrante; digo longo processo por que ele geralmente transcende a primeira geração. São as gerações seguintes que compreendem melhor este momento seminal na medida em que se sentem mais livres para transitar por outros territórios.

Entretanto, esta liberdade de transito não nos dá muitas pistas para compreender qual o tempo necessário ou sob qual ambiente a condição migrante deixa de ter uma influência significativa na constituição das identidades dos sujeitos. Ainda hoje, encontramos descendentes de terceira ou mesmo quarta geração que recorrem com freqüência ao passado migrante de suas famílias. Possivelmente os territórios migrantes não possam superar seu momento seminal de constituição por mais paradoxos, ambigüidades e contradições que este momento possua, dada a sua capacidade de ressignificação constante. Isto implica que, no plano das identidades, sejam elas individuais ou coletivas, ele permaneça como lugar (intangível) no qual há um repertório inesgotável de representações que podem ser usadas para a constituição das alteridades... mas isto já é uma outra história. 